Published in final edited form as:

Osteoporos Int. 2014 April ; 25(4): 1327-1335. doi:10.1007/s00198-013-2602-4.

\title{
Marital histories, marital support, and bone density: findings from the Midlife in the United States Study
}

\author{
D. Miller-Martinez, \\ Division of Geriatrics, David Geffen School of Medicine at University of California, Los Angeles, \\ 10945 Le Conte Avenue, Suite 2339, Los Angeles, CA 90095-1687, USA
}

\section{T. Seeman,}

Division of Geriatrics, David Geffen School of Medicine at University of California, Los Angeles, 10945 Le Conte Avenue, Suite 2339, Los Angeles, CA 90095-1687, USA

\section{A. S. Karlamangla,}

Division of Geriatrics, David Geffen School of Medicine at University of California, Los Angeles, 10945 Le Conte Avenue, Suite 2339, Los Angeles, CA 90095-1687, USA

\section{G. A. Greendale,}

Division of Geriatrics, David Geffen School of Medicine at University of California, Los Angeles, 10945 Le Conte Avenue, Suite 2339, Los Angeles, CA 90095-1687, USA

\section{N. Binkley, and \\ University of Wisconsin-Madison Osteoporosis Clinical Center and Research Program, Madison, WI, USA \\ C. J. Crandall \\ Division of General Internal Medicine and Health Services Research, David Geffen School of Medicine at University of California, Los Angeles, 911 Broxton Ave, 1st Floor, Los Angeles, CA 90024, USA \\ D. Miller-Martinez: danamill@ucla.edu; T. Seeman: tseeman@mednet.ucla.edu; A. S. Karlamangla: akarlamangla@mednet.ucla.edu; G. A. Greendale: ggreenda@mednet.ucla.edu; N. Binkley: nbinkley@wisc.edu; C. J. Crandall: ccrandall@mednet.ucla.edu}

\section{Abstract}

Summary-We examined the association between marital life history and bone mineral density (BMD) in a national sample from the US. In men, being stably married was independently associated with better lumbar spine BMD, and in women, more spousal support was associated with better lumbar spine BMD.

Introduction-Adult bone mass may be influenced by stressors over the life course. We examined the association between marital life history and bone mineral density (BMD) net socioeconomic and behavioral factors known to influence bone mass. We sought evidence for a gender difference in the association between marital history and adult BMD.

\footnotetext{
(C) International Osteoporosis Foundation and National Osteoporosis Foundation 2013

Correspondence to: C. J. Crandall, ccrandall@mednet .ucla.edu.

Conflicts of interest None.
} 
Methods-We used data from 632 adult participants in the Midlife in the United States Study to examine associations between marital history and BMD, stratified by gender, and adjusted for age, weight, menopausal stage, medication use, childhood socioeconomic advantage, adult financial status, education, physical activity, smoking, and alcohol consumption.

Results-Compared to stably married men, men who were currently divorced, widowed, or separated, men who were currently married but previously divorced, widowed, or separated, and never married men had 0.33 (95 \% CI: 0.01, 0.65), 0.36 (95\% CI: 0.10, 0.83), and 0.53 (95\% CI: $0.23,0.83$ ) standard deviations lower lumbar spine BMD, respectively. Among men married at least once, every year decrement in age at first marriage (under age 25) was associated with 0.07 SD decrement in lumbar spine BMD (95\% CI: 0.002, 0.13). In women, greater support from the spouse was associated with higher lumbar spine BMD.

Conclusions-Our findings suggest that marriage before age 25 and marital disruptions are deleterious to bone health in men, and that marital quality is associated with better bone health in women.

\section{Keywords}

Bone density; Marital history; Marital quality; Marital status; Osteoporosis

\section{Introduction}

The effect of psychosocial stressors over the life course on adult health is an important public health issue, particularly among the growing older population. By 2012, approximately 12 million Americans older than 50 years are expected to have osteoporosis. Approximately one in two postmenopausal women and one in five older men will experience an osteoporosis-related fracture [1]. Psychosocial stressors over the life course have been shown to influence biological systems which in turn influence health outcomes [2-4]. Bone mass accumulates throughout childhood and adolescence [5, 6], stays steady through midlife, and begins to decline in later years; therefore, psychosocial stressors over the entire life course may leave their mark on bone mass. A previous study of adult bone mass found that early life experience, specifically, childhood financial advantage, was positively associated with adult bone mass [7], lending support for a life course perspective that considers the influence of early life experiences on the acquisition of bone.

Marriage is often considered to have a health-protective effect and studies have found an association between being married and lower rates of chronic illness, fewer physical limitations, and less disability $[8,9]$. However, early marriage (often defined as marriage at 20 years of age or younger) is associated with greater psychosocial distress, lower educational attainment, and poorer long-term marital success [10,11]—all factors associated with lower bone strength and bone density $[12,13]$.

Previous studies of bone density have examined the association between bone density and current marital status, ignoring the influence of prior marital trajectories [14-16]. Marital disruption, either through divorce or widowhood, can be a source of psychosocial stress; however, subsequent remarriage or cohabitation may alleviate some of this stress over time. 
In order to understand potential long-term impacts of psychosocial stressors on bone outcomes, it is important to consider marital history, and not just current marital status. Additionally, there are gender differences in the experience of marriage as a source of psychosocial stress and/or psychosocial support $[17,18]$. For instance, though the evidence suggests both married men and women have lower psychological distress, the source of this association differs for men and women. Traditionally, marriage had provided women with improved economic security, and men with emotional support—both factors associated with less psychological distress [18]. Thus, it is important to consider possible gender differences in the effect of marital history on bone outcomes. The social support that marriage provides may also be less influential on health in women, who, compared to men, obtain social support from other sources outside of their spouse [17]. In addition to marital status per sé, the quality of the marriage may also be relevant to health [18] and to bone health in particular.

The objective of this study is to investigate the association of marital history and quality with adult bone density.

\section{Methods}

The MIDUS National Study of Health and Well-Being [19-21] recruited a national sample of adults between 25 and 75 years of age residing in the continental United States in 19951996. Participants were re-interviewed 9-10 years later, 2004-2006 (MIDUS II). Additional details of the study design, recruitment, and retention are available at http:// www.icpsr.umich.edu/icpsrweb/NACDA/. Of the 3,191 MIDUS II participants medically able to travel, 1,255 (39.3\%) agreed to participate in the MIDUS II Biomarker project, which included travel to one of the three clinical research centers: University of California at Los Angeles, Georgetown University, and University of Wisconsin. Participants' medical history information was obtained, in addition to anthropometric and biomarker and BMD measurements.

The characteristics of the MIDUS II participants were similar to those of the MIDUS I participants [21] and the characteristics of the MIDUS Biomarker project participants (e.g., subjective health status, chronic health conditions, exercise, alcohol use) were similar to those of the MIDUS II participants as a whole [19].

Of the 1,255 participants in the MIDUS II Biomarker Project, we excluded data from 126 participants who reported the use of medications known to influence bone density (oral corticosteroids, alendronate, anastrozole, calcitonin, ibandronate, leuprolide, letrozole, raloxifene, risedronate, tamoxifen, zoledronic acid, testosterone, finasteride, dutasteride), 137 women participants whose menopause transition stage classification could not be completed, 11 participants for whom marital history could not be determined, 254 without BMD measurement (which was added to the Biomarker Project partway into data collection), and 95 for whom we were missing data on other key covariates. Thus, the analytic sample for this study was composed of 632 participants (294 men, 338 women). Some models were run on slightly smaller samples due to missing data for predictors included in the models. 


\section{Marital history assessment}

To capture marital life history, we combined current marital status and marital history information from the MIDUS II Biomarker Project with additional historical information from MIDUS I. Using self-reported information from both waves, we categorized participants as: (1) currently married, and never before divorced, widowed, or separated; (2) currently married, but previously divorced, widowed, or separated; (3) currently divorced, widowed, or separated; or (4) never married. The term "current" in these category titles refers to the time of the MIDUS II Biomarker Project, when bone scans were obtained. Participants were also separately asked if they are living with someone "in a marriage-like situation". Those who reported they did at the time of the bone scan, but also reported being previously divorced, widowed, or separated were included in category 2 (currently married, previously divorced, widowed, or separated).

Additionally, participants who reported ever having been married also provided the age at which they were first married. We created a variable for the number of years a person was married before age 25. Among those married at either MIDUS I or MIDUS II, marital quality was assessed from responses to six questions regarding how much a person's spouse "really cares about you", "understands the way you feel", "appreciates you", and how much can you "rely on your spouse to help with serious problems", "open up to your spouse about your worries", and "relax and be yourself with your spouse [22] Responses choices were: a lot (4 points), some ( 3 points), a little ( 2 points), or not at all (1 point). Items were scored so that higher scores indicate higher support, and the mean score was created across items and across both waves of data. If the respondent was only married at one time point, the mean score for that one time point was used. Similar information was obtained about the level of social support from other sources, with mean scores created across items and across both waves of data. For participants who did not provide data at one of the two waves, we used the mean scores across items for the one available wave. Two sets of questions were asked separately about friends and about other family members: how much they "really care about you", "understand the way you feel", "appreciate you", and how much can you "rely on them to help with serious problems" were asked with same four response choices. The social support measures were internally consistent (Cronbach's alpha $=0.87,0.78$, and 0.77 for spouse, friend, and other family, respectively), and showed high levels of stability from MIDUS I to MIDUS II.

\section{Bone mineral density measurement}

At the MIDUS II visit (2004-2009), BMD was measured in the lumbar spine (L1-L4) and left hip using dual-energy X-ray absorptiometry (DXA). DXA scans were performed using GE Healthcare Lunar Prodigy (Madison site) or Hologic 4500 (UCLA and Georgetown) technology by technologists certified by the International Society for Clinical Densitometry. Funding for DXA scanning at the UCLA and Georgetown sites was obtained after the Biomarker Project had commenced; thus, BMD data were not available for every participant at these sites $(n=313)$. Adjudication of all DXA scans occurred centrally by physicians at the University of Wisconsin DXA center. Three times per week, and on all days on which scans were obtained, instruments were calibrated and phantom scan data were acquired. No densitometer shift or drift occurred during the course of this study. For BMD cross- 
calibration across the three clinical sites, a "bone-fide" phantom was scanned ten times on the densitometers at each of the three study sites. The linear regression equation developed from these calibration scans were used to correct BMD values from two of the three sites to make the data comparable across study sites. The re-calibrated BMD values at the lumbar spine and left hip were reported in units of grams per centimeter squared.

\section{Covariates}

From self-reported menstrual patterns and use (in the last year) of sex steroid hormones, we classified each female participant's menopausal stage as one of the following: premenopausal (regular menses with no change in regularity of menses), early perimenopausal (menses in last 3 months with change in regularity of menses), late perimenopausal (last menses 3-12 months previously with change in regularity of menses), postmenopausal (no menses in prior 12 months) not taking menopausal hormone therapy, or postmenopausal taking menopausal hormone therapy. Because there were very few women who were late perimenopausal in the sample, this group was combined with the postmenopausal not on hormone therapy group for analysis.

We classified men participants by age into one of three categories: younger than 50 years, age 50-59 years, 60 years or older. The choice of age categories in men was guided by previous observations that substantial age-related bone loss in men does not start until age 50 years [23], and to age-match the oldest male group to the postmenopausal women, because only $0.3 \%$ of occurrences of spontaneous menopause take place at or after 59 years of age [24].

We calculated a childhood socioeconomic advantage score (possible range 0-6) for each participant by summing three components: being on welfare during childhood (0: yes, 2 : no), childhood financial level relative to others ( 0 : worse off, 1: same, 2: better), and highest parental education ( 0 : <high school, 1: high school/general educational development [GED] certificate, 2: some college or more). Scores were calculated only for participants who supplied data for at least two of the three components. For 49 participants who were missing exactly one of the three components, the missing component was imputed as the rounded mean of the other two components.

The participants' own educational level was also ascertained and collapsed to a threecategory variable: (1) high school or less; (2) some college; (3) Bachelor's degree or more. Current family-adjusted poverty-to-income ratio (FPIR) for each participant was calculated as the ratio of the participant's total household income (sum of self-reported earnings, pension, social security, and government assistance for all household members) to the US Census Bureau poverty threshold that was specific to the participant's age, presence of a spouse or partner in the household, the number of children under age 18 living in the household, and year of data collection http://www.census.gov/hhes/www/poverty/data/ threshld/index.html. We calculated an overall adult current financial advantage score (possible range $0-8$ ) by summing four components: FPIR ( 0 for FPIR $<3,1$ for FPIR $\geq 3$ but $<6,2$ for FPIR $\varangle$, reflecting approximate tertiles of its distribution), self-rated current financial situation ( 0 : worst, 1 : average, 2 : best), money to meet needs ( 0 : not enough, 1 : just enough, 2: more than enough), and degree of difficulty paying bills (0: very, 1 : not very, 2 : 
not at all). Scores were calculated only for participants who supplied data regarding at least 3 of the 4 components; for 20 participants, the missing component was imputed as the rounded mean of the values of other three components for that participant

Race was self-reported as white, black/African American, other, or multiracial. For these analyses, we classified race as black vs. not black. Participants classified as non-black group were predominantly white, but a small number of participants in the non-black group were neither white nor black/African American ( $n=32,4.4 \%)$.

Questionnaires administered at the time of the BMD measurement assessed smoking history by asking the number of years the participant smoked regularly and the number of cigarettes smoked per day (pack years=years smoked regularly $\times$ number of cigarettes per day/20). Additionally, participants were asked about current smoking status (current smoker: 1, not: 0 ). Participants were also asked about the number of alcoholic drinks per week consumed in the year they drank the most. Based on gender, participants were coded heavy drinkers at peak if they reported 14 or more drinks per week for men, or seven or more drinks per week for women.

Participants were asked about their level of physical activity at three stages of life: high school, young adulthood, and current (at the time of BMD measurement). Participants were asked the number of years he/she participated in competitive and recreational sports (separately) between the ages of 14 and 18. Participants were asked the number of years of exercise for each of three intensity levels (light, moderate, and vigorous) during young adulthood (between ages 20-35). Participants were asked to report the average number of minutes per week currently spent doing light, moderate, and vigorous exercise. For each participant, we calculated a summary score for young adulthood and current levels of physical activity by adding the reported times for light (weight 1), moderate (weight 2), and vigorous (weight 3 ) activity. Prior studies have validated the use of similar (recalled) selfreports of physical activity http://www.census.gov/hhes/www/poverty/data/threshld/ index.html [25].

Weight in kilograms was measured during the physical exam.

\section{Statistical analysis}

Lumbar spine BMD and femoral neck BMD were the dependent variables in separate multivariate linear regressions that examined their association with marital status. One set of models examined current marital status (yes/no), another examined marital history (4 categories), a third examined age at first marriage (in those married at least once), and a fourth examined marital quality (among those ever married). All models controlled for gender, age categories in men ( $<50$ years, $50-59$ years, $\ 60$ years), menopause transition stage in women (premenopausal, early perimenopausal, late peri-/postmenopausal not taking hormone therapy, and post-menopausal taking hormone therapy), two continuous age variables to capture age-related declines in older adults (one that tracked age in men age 60 years and older, and one that tracked age in women who were late peri-/postmenopausal not taking hormone therapy), childhood socioeconomic advantage score and adult financial advantage score (both modeled as continuous predictors), education (high school or less, 
some college, college graduate or more), body weight (continuous), pack years of smoking, four continuous physical activity measures (two from high school years, one from young adulthood, and one for current activity), history of ever being a heavy drinker (yes/no), and any use of selective serotonin reuptake inhibitor medication.

Models were also run gender-stratified to capture hypothesized gender differences in the effect of marital history. The models examining the effect of early marriage, and marital quality were only examined for participants who were ever married. In addition, the models for marital quality included additional controls for marital history and support from other sources (friends and other family members). We used mixed liner effects models with a random intercept at the family level to account for clustering between siblings and twins using STATA 10.1 software (StataCorp LP, College Station, TX, USA).

\section{Results}

Compared with the complete Biomarker Project sample (Table 1), the analytic sample has a greater percentage of men ( $46.5 \%$ vs. $43.2 \%)$ and blacks (26.1\% vs. $17.7 \%)$. The African Americans from the city of Milwaukee were oversampled and were seen exclusively at the Madison site, which was also the first to initiate DXA scans. A plurality of the analytic sample had a stable marital history without disruptions: $42 \%$ reported being currently married and never before divorced, widowed, or separated, and a minority reported being never married $(13.5 \%)$. Of those who had ever been married, $66 \%$ reported having first gotten married before age 25 years. Mean age of first marriage among those married at least once was 24.1 years. Compared with men, women were less likely (33.7 vs. $51.0 \%$ ) to be stably married (currently married without being previously divorced, widowed, or separated), but more likely to have been never married (15.7 vs. $10.9 \%$ ) and have had marital disruptions: $15.7 \%$ of women compared to $21.8 \%$ of men were currently married but had previously been divorced, widowed, or separated, and $34.9 \%$ of women vs. $16.3 \%$ of men were currently divorced, widowed, or separated. Mean age at first marriage was higher in men (25.6 years) than in women (22.8 years).

Table 2 provides results for models with current marital status, marital histories, and marital support as primary predictors of lumbar spine BMD. Those who were currently married exhibited significantly higher lumbar spine BMD [0.19 standard deviation (SD) higher; 95 $\%$ CI: $0.03,0.35$ ] than those who were not currently married (Model 1: Table 2). However, the association between lumbar spine BMD and current marital status was only significant among men. Men currently married had 0.29 SD higher BMD (95 \% CI: 0.04, 0.53) compared with men not currently married. Marital status was not associated with femoral neck BMD (data not shown).

Those who had never married had 0.27 SD lower BMD at the lumbar spine (95 \% CI: -0.49 to -0.05), and those who are currently divorced, widowed, separated had 0.24 SD lower lumbar spine BMD (95\% CI: -0.42, -0.05) compared with participants who were currently married and never divorced, widowed, or separated (Table 2: Model 2). There was marginal evidence that the association between never married and lower BMD differed by gender $(p=0.08)$; thus, we ran stratified models. The gender-stratified models demonstrated that 
among men, those who were never married, and those currently married/previously divorced, widowed, separated had lower lumbar spine BMD (0.53 SD lower BMD, $95 \%$ CI: -0.83 to -0.23 , and 0.36 SD lower BMD, $95 \% \mathrm{CI}$ : -0.83 to 0.10 , respectively), but this was not the case among women (Model 2: Table 2).

Among those who were married at least once, the association between early marriage and BMD was also only significant for BMD in the lumbar spine (Model 3: Table 2) and not for BMD in the femoral neck (data not shown). Using the number of years married prior to age 25 as the primary exposure in regression models, we found that each extra year of marriage before age 25 was associated with 0.07 SD lower lumbar spine BMD (95\% CI: -0.13 to -0.002) among men. Among women, early age at first marriage (before age 25) was not associated with BMD at the lumbar spine or the femoral neck.

Finally, we examined the effect of marital quality on BMD outcomes. Again, significant associations between marital quality and bone were found at the lumbar spine (Model 4: Table 2) and not at the femoral neck (data not shown). In those who were married at least once, controlling for support from other sources (friends and other family members), a oneunit increase in spouse support was associated with 0.19 SD higher lumbar spine BMD (95 $\%$ CI: 0.01 to 0.37 ). Gender-stratified models demonstrated that this association was significant among the women, in whom each unit increase in spousal support was associated with 0.35 SD higher lumbar spine BMD (95\% CI: 0.10 to 0.59), but was not significant among men. We also tested the association in the smaller group of 214 participants who were married at both MIDUS I and MIDUS II (123 males, 91 females). The findings were similar, although only marginally significant $(p=0.06)$, showing an association between greater spousal support and higher lumbar spine BMD (0.58 SD higher BMD per unit increase in spousal support, $95 \% \mathrm{CI}:-0.004,1.17)$ among women.

\section{Discussion}

This analysis of marital history and BMD in mid-to late-life demonstrated that men who were never married, and those who experienced divorce, widowhood, or separation, had significantly lower BMD at the lumbar spine than men who were married and never experienced marital disruption. We also found that marrying at a young age was associated with lower lumbar spine BMD outcomes among men. Neither marital history nor early marriage was associated with BMD in women. On the other hand, greater marital quality was associated with greater lumbar spine BMD among women, but not among men, and the association in women was independent of the level of support received from friends and other family members.

The gender differences we observed in the association between marital history and BMD support the strong and consistent evidence that marriage is generally health protectiveassociated with lower mortality, better physical health, better psychological well-being, but more so for men than for women $[17,18,25]$. In women, the quality of the marriage was more important than just being married, consistent with previous findings that women unhappily married suffer more distress than those never married [18]. Overall, our findings 
extend the evidence for a beneficial relationship between marriage and health in men, and between marital quality and health in women.

Our finding that early age at first marriage was associated with poorer bone outcomes among men is similar to previous findings that women who married before age 19 were at greater risk for health problems [8]. It is possible that marriage in teenage years is detrimental to women's health while marriage in the early 20's is also detrimental to men's health. Unfortunately, the number of people in our sample who got married before age 19 was not large enough to test this hypothesis. Marrying young is associated with lower education trajectories, and financial disadvantage [8]. The men who marry in their early 20's or earlier likely experience greater stress trying to provide for their families with limited resources; this may explain the association seen between young age at first marriage and lower BMD in midlife.

The exact mechanism for gender differences in the association between marital history and BMD is unclear. Its elucidation requires longitudinal data of marital transition timings in the life course along with bone density data over the same time periods in order to tease apart the details of the association between marital trajectories and bone health [26]. Previous studies have shown gender differences in the relationship between "time since a marital transition" and onset of serious health conditions (diabetes, cancer, heart attack, or stroke) [8], and psychological distress [27]. Another study demonstrated gender differences in the relationship between the transition out of marriage and self-reported health [26]. The variation in stress associated with marital timing and transitions and subsequent effects on health outcomes may be due to differences in the kind of support marriage provides-men, generally, receive significant social support from their marital partner [28], whereas, women benefit more from the economic security marriage provides [9]. The theory that the economic security gained through marriage can benefit a woman's health may explain why marrying young was not associated with lower bone density in women in our study, since some economic benefits may accrue regardless of age at first marriage. If the economic security provided by marriage means that early marriage is not associated with worse bone health in women, being married by itself does not appear to positively benefit a woman's bone density. It is only when the marriage provides social support do women see bone density benefits.

In addition to social and psychological pathways, it is also important to consider biological explanations for the gender difference in the association between marital history and BMD. It is possible we did not see an association between marital history and BMD among women because large changes in BMD due to the hormonal changes associated with menarche, pregnancies, lactation, and menopause likely overwhelm the effect of psychosocial factors in women.

The consistently significant associations found at the lumbar spine but not at the femoral neck may be the result of differences in bone composition. Bone is predominantly trabecular at the lumbar spine, and more cortical at the femoral neck [29, 30]. Some studies suggest that cancellous vertebral bone mass is more strongly influenced by hormonal and/or metabolic factors that may, in turn, be influenced by stressors compared with cortical bone 
mass, which is largely influenced by weight-bearing and physical activity [30-32]. Prior studies have also found significant associations of education level with lumbar spine BMD, and no significant associations of education level with femoral neck BMD [7, 33]. It is also possible that the lumbar spine BMD associations with marital history/support seen here are the result of differences in the prevalence of spine osteoarthritis, rather than of differences in actual bone density in the spine. While we cannot rule out this possibility using these data, previous studies suggest that osteoarthritis is more prevalent in low SES and high stress populations [34, 35], which would lead to higher not lower spine BMD in low SES individuals, men with marital transition stress, and women with low levels of marital support. Our findings are in the other direction: lower spine BMD in men with a history of marital transitions and in women with less marital support, and thus not likely to be an artifact of osteoarthritis of the spine.

The current findings are somewhat limited by the lack of information regarding the timing and duration of marital states, which can be important in the experience of events as life stressors [26]. However, the current analyses using marital history is an improvement over studies that assess only current marital status which ignores the effect of having experienced a previous divorce, widowhood, or separation, an important consideration for bone mass which changes slowly and can be expected to show long-term effects of past exposures. Other limitations of the study include the lack of longitudinal assessments of bone density which limits our ability to draw causal inferences, and the restriction that participants be medically fit for travel which limits the generalizability of our findings. Although the participation rate among those medically able to travel was just under $40 \%$, the Biomarker Project sample was very similar to the complete MIDUS II Sample with respect to major demographic variables [19], and our study sample was similar to the Biomarker sample, supporting the internal validity of findings. Yet, the small size of some groups (e.g., those never married) limited our ability to detect other latent associations, especially in the gender-stratified analyses.

Despite the above limitations, this is the first study to have demonstrated a strong link between marital life history and adult bone health. These findings provide additional new evidence of the association between psychosocial life histories and adult bone health. The gender differences observed in the association between marital history and BMD are consistent with gender differences seen in previous studies of marital status and other aspects of health, and imply that we should not assume that marriage has the same health rewards for men and women. Specifically, never marrying, and experiencing a divorce, widowhood, or separation are associated with poor bone health in men, whereas poor marital quality is associated with poor bone health in women. Future research should examine the impact of timing, number, and duration of marital transitions to better understand the association between marital life history and bone health and how the association differs by gender.

\section{Acknowledgments}

This research was supported by National Institutes of Health grant numbers 1R01AG033067, R01-AG-032271, and P01-AG-020166. The research was further supported by the following grants M01-RR023942 (Georgetown), M01RR00865 (UCLA), from the General Clinical Research Centers Program and 1UL1RR020511 (UW) from the 
Clinical and Translational Science Award (CTSA) program of the National Center for Research Resources, National Institutes of Health. Dr. Crandall received support from the Jonsson Comprehensive Cancer Center at the University of California, Los Angeles.

\section{References}

1. USPSTF. Screening for osteoporosis: U.S. preventive services task force recommendation statement. Ann Intern Med. 2011; 154:356-364. [PubMed: 21242341]

2. Gruenewald TL, Karlamangla AS, Hu P, Stein-Merkin S, Crandall C, Koretz B, Seeman TE. History of socioeconomic disadvantage and allostatic load in later life. Soc Sci Med. 2012; 74:7583. [PubMed: 22115943]

3. Seeman TE, McEwen BS, Rowe JW, Singer BH. Allostatic load as a marker of cumulative biological risk: MacArthur studies of successful aging. Proc Natl Acad Sci U S A. 2001; 98:47704775. [PubMed: 11287659]

4. Seeman TE, Singer BH, Rowe JW, Horwitz RI, McEwen BS. Price of adaptation-allostatic load and its health consequences. MacArthur studies of successful aging. Arch Int Med. 1997; 157:22592268. [PubMed: 9343003]

5. Foundation NO. Clinician's guide to prevention and treatment of osteoporosis. National Osteoporosis Foundation; Washington, DC: 2013.

6. Heaney RP, Abrams S, Dawson-Hughes B, Looker A, Marcus R, Matkovic V, Weaver C. Peak bone mass. Osteoporos Int. 2000; 11:985-1009. [PubMed: 11256898]

7. Crandall CJ, Merkin SS, Seeman TE, Greendale GA, Binkley N, Karlamangla AS. Socioeconomic status over the life-course and adult bone mineral density: the Midlife in the U.S. Study. Bone. 2012; 51:107-113. [PubMed: 22543227]

8. Dupre M, Meadow SO. Disaggregating the effects of marital trajectories on health. Journal of Family Issues. 2007; 28:623-652.

9. Lillard W. Til death do us part: marital disruption and mortality. Am J Sociol. 1995; 100:11311156.

10. Hope S, Rodgers B, Power C. Marital status transitions and psychological distress: longitudinal evidence from a national population sample. Psychol Med. 1999; 29:381-389. [PubMed: 10218928]

11. Uecker JE, Stokes CE. Early marriage in the United States. J Marriage Fam. 2008; 70:835-846. [PubMed: 20305796]

12. Karlamangla AS, Mori T, Merkin SS, Seeman TE, Greendale GA, Binkley N, Crandall CJ. Childhood Socioeconomic Status and Adult Femoral Neck Bone Strength: Findings from The Midlife in the United States Study. Bone. 2013

13. Brennan SL, Pasco JA, Urquhart DM, Oldenburg B, Wang Y, Wluka AE. Association between socioeconomic status and bone mineral density in adults: a systematic review. Osteoporos Int. 2011; 22:517-527. [PubMed: 20449573]

14. Farahmand BY, Persson PG, Michaelsson K, Baron JA, Parker MG, Ljunghall S. Socioeconomic status, marital status and hip fracture risk: a population-based case-control study. Osteoporos Int. 2000; 11:803-808. [PubMed: 11148808]

15. Meyer HE, Tverdal A, Falch JA. Risk factors for hip fracture in middle-aged Norwegian women and men. Am J Epidemiol. 1993; 137:1203-1211. [PubMed: 8322761]

16. Nabipour I, Cumming R, Handelsman DJ, et al. Socioeconomic status and bone health in community-dwelling older men: the CHAMP Study. Osteoporos Int. 2011; 22:1343-1353. [PubMed: 20571771]

17. Gove WR. Gender differences in mental and physical illness: the effects of fixed roles and nurturant roles. Soc Sci Med. 1984; 19:77-91. [PubMed: 6474235]

18. Ross, M Goldsteen. The Impact of the Fam on Health: The Decade in Rev. J Fam and the Fam. 1990; 52:1059-1078.

19. Dienberg Love G, Seeman TE, Weinstein M, Ryff CD. Bioindicators in the MIDUS national study: protocol, measures, sample, and comparative context. J Aging Health. 2010; 22:1059-1080.

[PubMed: 20876364] 
20. Brim, OG.; Ryff, CD.; Kessler, RC. How healthy are we? A national study of well-being at midlife. University of Chicago Press; Chicago: 2004.

21. Radler BT, Ryff CD. Who participates? Accounting for longitudinal retention in the MIDUS national study of health and well-being. J Aging Health. 2010; 22:307-331. [PubMed: 20103686]

22. Schuster TL, Kessler RC, Aseltine RH Jr. Supportive interactions, negative interactions, and depressed mood. Am J Community Psychol. 1990; 18:423-438. [PubMed: 2264558]

23. Riggs BL, Wahner HW, Dunn WL, Mazess RB, Offord KP, Melton LJ 3rd. Differential changes in bone mineral density of the appendicular and axial skeleton with aging: relationship to spinal osteoporosis. J Clin Invest. 1981; 67:328-335. [PubMed: 7462421]

24. Treloar AE. Menstrual cyclicity and the pre-menopause. Maturitas. 1981; 3:249-264. [PubMed: 7334935]

25. Campbell TL. Research reports: marriage and health. Fam Syst Med. 1993; 11:303-309.

26. Williams K, Umberson D. Marital status, marital transitions, and health: a gendered life course perspective. J Health Soc Behav. 2004; 45:81-98. [PubMed: 15179909]

27. Booth A, Amato P. Divorce and psychological stress. J Health Soc Behav. 1991; 32:396-407. [PubMed: 1765629]

28. Gerstel NRC, Rosenfield S. Explaining the sumptomatology of separated and divorced men and women: the role of material conditions and social networks. Oxford J. 1985; 64:84-101.

29. Rosen, CJ. American Society for Bone and Mineral Research. Primer on the metabolic bone diseases and disorders of mineral metabolism. American Society for Bone and Mineral Research; Washington, D.C: 2009.

30. Mora S, Goodman WG, Loro ML, Roe TF, Sayre J, Gilsanz V. Age-related changes in cortical and cancellous vertebral bone density in girls: assessment with quantitative CT. AJR Am J Roentgenol. 1994; 162:405-409. [PubMed: 8310936]

31. Nilsson M, Ohlsson C, Mellstrom D, Lorentzon M. Previous sport activity during childhood and adolescence is associated with increased cortical bone size in young adult men. $\mathrm{J}$ Bone Miner Res. 2009; 24:125-133. [PubMed: 18767931]

32. Ott SM. Bone density in adolescents. N Engl J Med. 1991; 325:1646-1647. [PubMed: 1944454]

33. Lauderdale DS, Rathouz PJ. Does bone mineralization reflect economic conditions? An examination using a national US sample. Econ Hum Biol. 2003; 1:91-104. [PubMed: 15463966]

34. Adler NE, Ostrove JM. Socioeconomic status and health: what we know and what we don't. Ann N Y Acad Sci. 1999; 896:3-15. [PubMed: 10681884]

35. American Psychological Association. Resolution on poverty and socioeconomic status. American Psychological Association; Washington, DC: 2000. 
Table 1

MIDUS marital history and BMD analytic sample

\begin{tabular}{|c|c|c|}
\hline & $\begin{array}{r}\text { Analytic sample }(n=632) \\
\text { Mean (SD) or number }(\%)\end{array}$ & MIDUS biomarker study $(n=1,255)$ \\
\hline Age (years) & $56.5(11.3)$ & $57.3(11.5)$ \\
\hline \multicolumn{3}{|l|}{ Females } \\
\hline Premenopausal & $61(18.1)$ & - \\
\hline Early perimenopausal & $50(14.8)$ & - \\
\hline Late peri- or postmenopausal not taking hormones & $197(58.3)$ & - \\
\hline Postmenopausal taking exogenous female sex steroids & $30(8.88)$ & - \\
\hline Total & $338(53.5)$ & $713(56.8)$ \\
\hline \multicolumn{3}{|l|}{ Males } \\
\hline$<50$ years old & $96(32.7)$ & $156(28.8)$ \\
\hline $50-59$ years old & $85(28.9)$ & $153(28.2)$ \\
\hline 260 years old & $113(38.4)$ & $233(43.0)$ \\
\hline Total & $294(46.5)$ & $542(43.2)$ \\
\hline \multicolumn{3}{|l|}{ Race/ethnicity } \\
\hline Non-black & $467(74.0)$ & $1,031(82.3)$ \\
\hline Black & $165(26.1)$ & $222(17.7)$ \\
\hline \multicolumn{3}{|l|}{ Education } \\
\hline High school or less & $184(29.1)$ & $344(27.7)$ \\
\hline Some college & $184(29.1)$ & $371(29.9)$ \\
\hline College graduate or more & $264(41.8)$ & $527(42.4)$ \\
\hline \multicolumn{3}{|l|}{ Marital status } \\
\hline Currently married, never previously divorced/widowed/separated & $264(41.8)$ & $543(43.8)$ \\
\hline Currently married, previously divorced/widowed/separated & $117(18.5)$ & $260(21.0)$ \\
\hline Currently divorced/widowed/separated & $166(26.3)$ & $305(24.6)$ \\
\hline Never married & $85(13.5)$ & $132(10.7)$ \\
\hline Age at first marriage (years) ${ }^{a}$ & $23.8(5.6)$ & $24.1(6.0)$ \\
\hline Married before age 25 & $350(65.5)$ & $746(68.4)$ \\
\hline Lumbar Spine BMD $\left(\mathrm{g} / \mathrm{cm}^{2}\right)$ & $1.06(0.18)$ & - \\
\hline Femoral Neck BMD $\left(\mathrm{g} / \mathrm{cm}^{2}\right)$ & $0.843(0.14)$ & - \\
\hline Weight $(\mathrm{kg})$ & $86.6(20.7)$ & $84.7(20.3)$ \\
\hline Current financial advantage score $(0-8)$ & $3.89(2.49)$ & $4.05(2.47)$ \\
\hline Childhood advantage score $(0-6)$ & $4.05(1.49)$ & $4.04(1.48)$ \\
\hline Competitive sports as child (years) & $1.77(1.78)$ & $1.63(1.77)$ \\
\hline Recreational sports as child (years) & $1.66(1.86)$ & $1.64(1.84)$ \\
\hline Physical activity as young adult $(0-90)$ & $34.6(25.7)$ & $33.3(26.0)$ \\
\hline Current physical activity $(0-14,490)$ & 709 (1239) & $638(1090)$ \\
\hline Pack years $(0-160)$ & $8.89(17.2)$ & $8.82(16.9)$ \\
\hline Current smoker & $104(16.5)$ & $187(14.9)$ \\
\hline Heavy drinker at peak use (yes/no) & $230(36.4)$ & $399(32.1)$ \\
\hline
\end{tabular}




\begin{tabular}{lrl}
\hline & $\begin{array}{r}\text { Analytic sample }(\boldsymbol{n = 6 3 2}) \\
\text { Mean (SD) or number }(\%)\end{array}$ & MIDUS biomarker study $(\boldsymbol{n = 1 , 2 5 5})$ \\
\hline Average support from spouse (1-4) & $3.61(0.51)$ & $3.60(0.51)$ \\
Average support from other family (1-4) & $3.45(0.57)$ & $3.47(0.56)$ \\
Average support from friends (1-4) & $3.27(0.65)$ & $3.28(0.63)$ \\
Research site & & \\
$\quad$ University of California, Los Angeles & $213(33.7)$ & $433(34.5)$ \\
University of Wisconsin & $322(51.0)$ & $533(42.5)$ \\
Georgetown University & $97(15.4)$ & $289(23.0)$ \\
\hline
\end{tabular}

The two main reasons for exclusion from the analytic sample were missing BMD measurement and unknown menopausal stage classification

${ }^{a}$ These data are based on participants who were married at least once and recalled their age at first marriage ( $n=534$ in the analytic sample and 1,090 in the Biomarker Project sample) 


\section{Table 2}

Effect size and $95 \%$ confidence interval for adjusted associations of various aspects of marital status and lumbar spine BMD. Effect sizes expressed in multiples of the BMD standard deviation (SD)

\begin{tabular}{|c|c|c|c|}
\hline & Full sample & Men & Women \\
\hline \multicolumn{4}{|l|}{ Model 1: Marital status ${ }^{a}$} \\
\hline Currently married $b$ & $0.19^{*}(0.03,0.35)$ & $0.29^{*}(0.04,0.53)$ & $0.12(-0.09,0.32)$ \\
\hline \multicolumn{4}{|l|}{ Model 2: Marital history ${ }^{a}$} \\
\hline Married: previously divorced, widowed, or separated ${ }^{c}$ & $-0.19^{\sim}(-0.52,0.14)$ & $-0.36^{*}(-0.83,0.10)$ & $0.11(-0.54,0.32)$ \\
\hline Currently divorced, widowed, or separated ${ }^{c}$ & $-0.24^{*}(-0.42,-0.05)$ & $-0.33^{\sim}(-0.65,-0.01)$ & $-0.18(-0.41,0.05)$ \\
\hline Never married ${ }^{c}$ & $-0.27^{*}(-0.49,-0.05)$ & $-0.53^{* *}(-0.83,-0.23)$ & $-0.09(-0.39,0.22)$ \\
\hline \multicolumn{4}{|l|}{ Model 3: Early marriage ${ }^{a, d}$} \\
\hline Per year of marriage prior to age 25 & $-0.03^{\sim}(-0.07,0.00)$ & $-0.07^{*}(-0.13,-0.002)$ & $-0.02(-0.06,0.03)$ \\
\hline \multicolumn{4}{|l|}{ Model 4: Marital quality $a, d, e$} \\
\hline Average spouse support (per unit increase in Likert scale) & $0.19^{*}(0.01,0.37)$ & $0.12(-0.20,0.44)$ & $0.35^{* *}(0.10,0.59)$ \\
\hline
\end{tabular}

${ }^{a}$ All models adjusted for age, gender, race, education, financial advantage, clinic site, body weight, menopause transition stage, smoking status, physical activity, and use of serotonin reuptake inhibitors

${ }^{b}$ Currently married (regardless of previous divorce of separation) versus everyone else

${ }^{c}$ Reference group $=$ currently married: never divorced, widowed, or separated

${ }^{d}$ Among those ever married

${ }^{e}$ Includes additional control variables for marital history, and support from other sources. Due to missing data regarding support, $n$ 's for these models are: 388 (full sample), 202 (males), 186 (females)

$\tilde{p}<0.10$

* $p<0.05$;

$* *<0.01$ 